\title{
Novel functional roles for PERIANTHIA and SEUSS during floral organ identity specification, floral meristem termination, and gynoecial development
}

\author{
April N. Wynn ${ }^{1,2}$, Andrew A. Seaman ${ }^{1}$, Ashley L. Jones ${ }^{1,3}$ and Robert G. Franks ${ }^{1 *}$ \\ 1 Department of Plant and Microbial Biology, North Carolina State University, Raleigh, NC, USA \\ 2 Department of Biology, Saint Mary's College of Maryland, St. Mary's City, MD, USA \\ ${ }^{3}$ Department of Plant Biology, University of Texas, Austin, TX, USA
}

\section{Edited by: \\ Zhongchi Liu, University of \\ Maryland, USA}

Reviewed by:

Mark Paul Running, University of Louisville, USA

Beth Allyn Krizek, University of

South Carolina, USA

${ }^{*}$ Correspondence:

Robert G. Franks, Department of Plant and Microbial Biology, North Carolina State University, 2548 Thomas Hall, Campus Box 7614, Raleigh, NC 27695-7614, USA e-mail: rgfranks@ncsu.edu
The gynoecium is the female reproductive structure of angiosperm flowers. In Arabidopsis thaliana the gynoecium is composed of two carpels that are fused into a tube-like structure. As the gynoecial primordium arises from the floral meristem, a specialized meristematic structure, the carpel margin meristem (CMM), develops from portions of the medial gynoecial domain. The CMM is critical for reproductive competence because it gives rise to the ovules, the precursors of the seeds. Here we report a functional role for the transcription factor PERIANTHIA (PAN) in the development of the gynoecial medial domain and the formation of ovule primordia. This function of PAN is revealed in pan aintegumenta (ant) as well as seuss (seu) pan double mutants that form reduced numbers of ovules. Previously, PAN was identified as a regulator of perianth organ number and as a direct activator of AGAMOUS (AG) expression in floral whorl four. However, the seu pan double mutants display enhanced ectopic $A G$ expression in developing sepals and the partial transformation of sepals to petals indicating a novel role for PAN in the repression of $A G$ in floral whorl one. These results indicate that PAN functions as an activator or repressor of $A G$ expression in a whorl-specific fashion. The seu pan double mutants also display enhanced floral indeterminacy, resulting in the formation of "fifth whorl" structures and disruption of WUSCHEL (WUS) expression patterns revealing a novel role for SEU in floral meristem termination.

Keywords: ovule, gynoecium, flowers, agamous, wuschel, organ identity, indeterminate growth

\section{INTRODUCTION}

In Arabidopsis thaliana, as with most angiosperms, reproductive competence depends on the proper development of the flower. Arabidopsis flowers develop from floral meristems, specialized structures that contain organized groups of undifferentiated cells that give rise to the four types of floral organs: sepals, petals, stamens, and carpels (Vaughn, 1955; Hill and Lord, 1988; Bowman et al., 1989). These four organ types develop in concentricallyorganized circular fields, termed whorls. Each organ type is produced in a separate whorl of the flower: four sepals in the exterior-most whorl (whorl 1); four petals (whorl 2); six stamens (whorl 3); and finally two carpels in the inner-most whorl (whorl 4).

The proper development of the complete complement of 16 floral organs requires a balance within the floral meristem between the generation of floral organ primordia and the maintenance or renewal of undifferentiated stem cells (Sablowski, 2007). After the initiation of the two carpels in the innermost whorl, the floral meristem terminates. Thus, the ability of the floral meristem to produce cells that will become floral organs is temporally-limited and is genetically-predetermined. This type of developmental floral program is termed a determinate program and generates a fixed number of floral organs. A failure to terminate the floral meristem can result in indeterminacy, or the formation of additional (supernumerary) organs in the central-most positions of the flower.

\section{AGAMOUS SPECIFIES STAMEN AND CARPEL IDENTITY AND BRINGS ABOUT TERMINATION OF THE FLORAL MERISTEM}

AGAMOUS ( $A G$ ) encodes a MADS-domain containing protein that plays at least two key roles during floral genesis: participation in regulatory complexes that specify the identity of stamens and carpels; and bringing about termination of the floral meristem and thus generating a determinant floral structure (Yanofsky et al., 1990; Bowman et al., 1991, 2012; Coen and Meyerowitz, 1991; Drews et al., 1991; Meyerowitz et al., 1991). Loss of $A G$ activity results in indeterminate flowers within which additional whorls of floral organs are generated from perdurant meristematic cells.

$A G$ is predominately expressed in the inner-most two whorls of the flower (whorls 3 and 4) in the cells that will give rise to the stamens and carpels (Yanofsky et al., 1990). At least three genes have been shown to have a role in the activation of $A G$ transcription within the flower: LEAFY (LFY) (Weigel and Meyerowitz, 1993); WUSCHEL (WUS) (Lenhard et al., 2001) and PERIANTHIA (PAN) (Das et al., 2009; Maier et al., 2009). All three directly bind to cis-regulatory elements located in the $A G$ second intron (Busch et al., 1999; Lohmann et al., 2001; Das et al., 2009; Maier 
et al., 2009). pan single mutant plants exhibited an incompletely penetrant floral meristem indeterminacy phenotype (Das et al., 2009) and the penetrance and severity of pan phenotypes are modified by environmental growth conditions, particularly day length (Maier et al., 2009). Additionally pan mutant phenotypes are enhanced by hypomorphic lfy alleles, indicating a functional similarity between $L F Y$ and $P A N$ during the activation of $A G$ (Das et al., 2009).

\section{REPRESSION OF AG IN WHORLS ONE AND TWO}

A number of genes have been shown to play a role in the repression of $A G$ within floral whorls one and two (for review see Liu and Mara, 2010). One of these genes, SEUSS (SEU), encodes a transcriptional adaptor protein, that physically interacts with several MADS domain proteins including APETALA1 (AP1), SEPALLATA3 (SEP3), AGAMOUS-LIKE24 (AGL24) and SHORT VEGETATIVE PHASE (SVP) (Sridhar et al., 2004; Gregis et al., 2006; Sridhar et al., 2006; Gregis et al., 2009). As a transcriptional adaptor, SEU is not thought to bind DNA directly but rather is recruited to cis-regulatory elements located within the $A G$ second intron through interactions with these MADS domain containing DNA transcriptional regulators (Liu and Meyerowitz, 1995; Franks et al., 2002; Gregis et al., 2006; Sridhar et al., 2006). SEU functions as a bridging protein that recruits the transcriptional repressor LEUNIG (LUG) to the complex and brings about transcriptional repression of $A G$ in whorls one and two (Sridhar et al., 2004, 2006). seu mutants display weak homeotic transformations of perianth organs caused by ectopic expression of $A G$ in the perianth, as well as a variety of additional pleiotropic phenotypes (Franks et al., 2002). SEU is widely expressed within the developing plant and likely functions in many developmental events.

\section{SEU AND ANT FUNCTION DURING THE DEVELOPMENT OF THE GYNOECIAL MEDIAL DOMAIN}

In Arabidopsis thaliana the female reproductive floral structure is the gynoecium, a composite structure formed from the congenital fusion of two carpel organs into a tubelike structure (Bowman et al., 1999). A specialized meristematic tissue termed the carpel margin meristem (CMM) develops within the medial portions of the gynoecial tube and gives rise to ovules (Bowman et al., 1999; Liu et al., 2000; Azhakanandam et al., 2008). The ovules are the immature, prefertilized precursors of seeds. Many groups have contributed to the understanding of the molecular mechanisms that support the specification and development of the medial gynoecial domain and the subsequent initiation of ovules (reviewed in Reyes-Olalde et al., 2013), but our mechanistic understanding of this important developmental process is incomplete.

$S E U$, in addition to its function in the specification of floral organ identity through the repression of $A G$, functions to promote ovule formation in the CMM (Azhakanandam et al., 2008). SEU works in a partially redundant manner with AINTEGUMENTA (ANT), another transcription factor, to regulate the expression of downstream genes critical for the formation of ovules (Azhakanandam et al., 2008; Wynn et al., 2011).
In contrast to $S E U$ which does not have a DNA binding domain (Sridhar et al., 2006), ANT encodes an AP2-like transcription factor containing a sequence-specific DNA binding domain. ANT activity supports the establishment of proper organ size in lateral organs by controlling the period of developmental time during which cells of the organ primordia are competent to grow and divide (Elliott et al., 1996; Klucher et al., 1996; Mizukami and Fischer, 2000; Nole-Wilson and Krizek, 2000; Krizek and Eaddy, 2012). The loss of either SEU or ANT activity, individually, results in a reduction of ovule number, however, the combined loss of SEU and ANT activity results in the complete loss of ovule formation (Azhakanandam et al., 2008).

Although both SEU and ANT function in $A G$ repression, it is unlikely that the alteration of CMM development in the seu ant double mutant is due to the de-repression of $A G$ expression (Azhakanandam et al., 2008). Rather additional gene regulatory alterations in the seu ant double mutants are likely to engender the altered development of the medial domain. Published transcriptomics experiments have identified genes that are misregulated in the seu ant gynoecia relative to the single mutant parents (Wynn et al., 2011). Many of these genes are expressed within the developing medial gynoecial domain and thus are likely candidates for regulators of medial domain development. PAN encodes one such candidate. PAN is a member of the bZIP transcription factor super-family of proteins (Hurst, 1995; Chuang et al., 1999). pan mutants display alterations in the spacing, position, and number of perianth organs formed, but do not condition a severe gynoecial phenotype (Running and Meyerowitz, 1996; Meyerowitz, 1997; Roe et al., 1997; Chuang et al., 1999; Maier et al., 2009, 2011; Wynn et al., 2011). As $P A N$ is expressed strongly in the developing gynoecial medial domain, placenta, and ovules is it possible that PAN plays a functional role during gynoecial development that is not observed in the pan single mutant due to functional redundancy.

In order to better assay the functional role of PAN during gynoecial development, we have generated seu pan and pan ant double mutant plants and examined floral development with a focus on gynoecial development and ovule formation. Our analyses of seu pan and pan ant double mutants indeed support the tenet that PAN plays a functional role during gynoecial and ovule development that can be revealed when either the activity of $S E U$ or of $A N T$ is compromised. We also report that $S E U$ plays a previously unanticipated role in floral meristem termination. This is revealed by altered patterns of WUS expression and the strong enhancement of the PAN indeterminacy phenotype in the seu pan double mutants, particularly under short-day conditions. Additionally, our data suggests that PAN can act as a repressor of $A G$ within sepals, in contrast to previous work indicating a role for $P A N$ in the activation of $A G$ in whorl 4. Our data suggest that both $P A N$ and $S E U$ have whorl-specific functions during the regulation of $A G$ that are critical for generating the Arabidopsis flower. Furthermore, the role of PAN and SEU during both floral meristem termination and CMM development suggest a possible link between these developmental events. 


\section{MATERIALS AND METHODS PLANT MATERIAL AND GROWTH CONDITIONS}

Plants were grown under long-day conditions of $16 \mathrm{~h}$ of light or under short-day conditions of $8 \mathrm{~h}$ of light. Temperature in the growth chambers were kept between 22 and $26^{\circ} \mathrm{C}$, however the temperature experienced by the plants is lower when the lights are off, thus short-day grown plants may be grown at a slightly lower average temperature than long-day grown plants. The ant-1 and seu-3 alleles were previously characterized (Klucher et al., 1996; Pfluger and Zambryski, 2004). The pan alleles used are SALK_031380, SAIL_247, and SALK_057190 with T-DNA insertions in the $5^{\prime} \mathrm{UTR}, 7$ th intron and the 3rd intron, respectively, (McElver et al., 2001; Sessions et al., 2002; Alonso et al., 2003). PCR was used to confirm genotypes (Table 1). The pan 057190 (SALK_057190) allele was previously characterized as a RNA null allele via in situ hybridization to inflorescence and floral tissues (Maier et al., 2009, 2011). Plants for rosette leaf counts were grown under short-day conditions until after bolting. Rosette leaves were removed, with care to only count rosette leaves and not axillary, cauline, or cotyledon leaves.

\section{IN SITU HYBRIDIZATION}

The protocol for in situ hybridization was described previously (Wynn et al., 2011). A more detailed protocol is located at http://www4.ncsu.edu/ rgfranks/research/protocols. html. The $A G$ antisense probe was in vitro transcribed using the T7 promoter from the pCIT565 plasmid linearized with HindIII. The $A G$ antisense probe generated is complementary to the $A G$ cDNA sequence from +140 (relative to the ATG) through the $3^{\prime}$ end of cDNA. The antisense WUS probe is complementary to the entire WUS cDNA clone and is derived from BamHI cut pMHwus16 plasmid, a gift of Jenn Fletcher. The $A G$ sense strand control probe was generated from a linearized pCIT565 plasmid (cut with XhoI) using the Sp6 promoter and contains the full length cDNA sequences. To generate the PAN antisense probe, the plasmid G50929 (ABRC) a full-length sequence-confirmed ORF/cDNA clone (Yamada et al., 2003) was cut with SalI to linearize and then the antisense probe was generated using the T7 polymerase. Due to the position of the SalI site, the PAN antisense probe generated is complementary to sequences from +746 through +1353 relative to the ATG start codon in the PAN cDNA.

\section{TISSUE FIXING AND CLEARING}

Tissue was fixed in 9 parts ethanol: 1 part acetic acid for $2 \mathrm{~h}$, then washed in $90 \%$ ethanol twice. Gynoecia were hand-dissected in ethanol and then moved into Hoyer's solution (70\% ethanol, 5\% gum arabic, $4 \%$ glycerol) for clearing and mounting on slides for visualization. Slides were examined with an Axioscop2 microscope (Zeiss) with Nomarski optics. Ovule counts were made from stages 11-14 gynoecia fixed on slides. Analysis of carpel bending and splitting was done under dissecting scope. Gynoecia were rated from 1 to 4 independently for bending as well as splitting. A severity score was given based on the following scoring system: 1 , no defect; 2 , mild defect; 3 , moderate defect; 4 , severe defect. All gynoecia were scored by the same individual, at the same time without knowledge of the genotype. All photos were captured with Q Capture software on a 5.0 RTV digital camera (Q Imaging, Surrey, BC, Canada). Data analysis was conducted in JMP Pro 10 (SAS Institute Incorporated, Cary, NC, USA) using multiple pair-wise comparison of the means with a Tukey-Kramer HSD test at an alpha of 0.05 or with a Student's T-test.

\section{RESULTS \\ pan MUTANT ALLELES CONDITION ENHANCED REDUCTION OF OVULE NUMBER IN seu AND ant MUTANT BACKGROUNDS}

In order to assay gynoecial development in pan mutant plants we characterized three available pan alleles (See Materials and Methods, Table 1) (McElver et al., 2001; Sessions et al., 2002; Alonso et al., 2003). Under our long-day growth conditions Col0 plants averaged $46.9 \pm 5.9$ ovules per gynoecium. As has been previously reported, ant single mutants displayed significantly fewer $(35 \pm 8.7)$ ovules per gynoecium (Figure 1A) (Elliott et al., 1996; Klucher et al., 1996; Azhakanandam et al., 2008). Previously published characterizations of pan mutants did not report a reduction in ovule formation. We counted ovule primordia in the gynoecia of three different pan mutant alleles (Figure 1A). Although we detected slight reductions in ovule number in two out of three of the pan alleles we tested, these differences were not statistically different from Col-0. However, all three of these pan mutant alleles conditioned an enhancement of ovule loss in the ant mutant background (Figure 1A). Thus, in the ant mutant background PAN appears to provide an activity that supports ovule formation.

In a second set of experiments, we examined the function of $P A N$ in the seu mutant background by assaying seu pan double

Table 1 | Genotyping primers.

\begin{tabular}{|c|c|c|c|c|}
\hline Allele name & $\begin{array}{l}\text { Genotyping Oligos FW } \\
\left(5^{\prime}-3^{\prime}\right)\end{array}$ & $\begin{array}{l}\text { Genotyping Oligo RV } \\
\left(5^{\prime}-3^{\prime}\right)\end{array}$ & $\begin{array}{l}\text { Genotyping Oligo } \\
\text { internal }\end{array}$ & $\begin{array}{l}\text { Size of Fragments } \\
\text { (in base pairs) }\end{array}$ \\
\hline ant-1 & TTCССТCAAACCAGAAACCA & GGGCTCATGGATAAGCTCAG & N/A & Wt: $131 \mathrm{bp} \mathrm{Mu}$ \\
\hline pan 031380 (in 5' UTR) & CGGTAACACACATGACACATATG & ATGGTGAAAACCATTGACTGG & LbB1 & Wt: 1228 Mutant: 550 \\
\hline pan SAIL_247 (in 7th intron) & TTGCCTCAATAAATCAGCCTG & GAATTCTTGGCAGACACTTCG & pCSA110LB2 & Wt: 1138 Mutant: 500 \\
\hline
\end{tabular}

The oligonucleotides and size of the PCR fragments from genotyping for each of the alleles we utilized in this paper. 


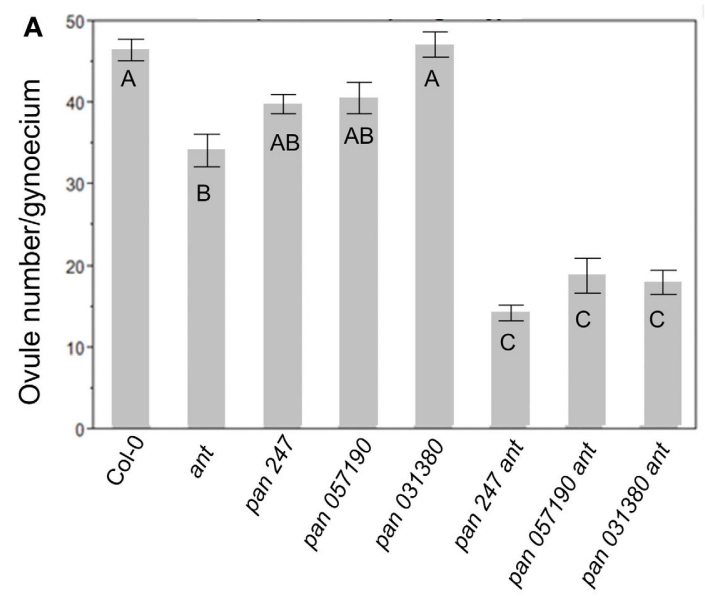

Genotype under long-day growth

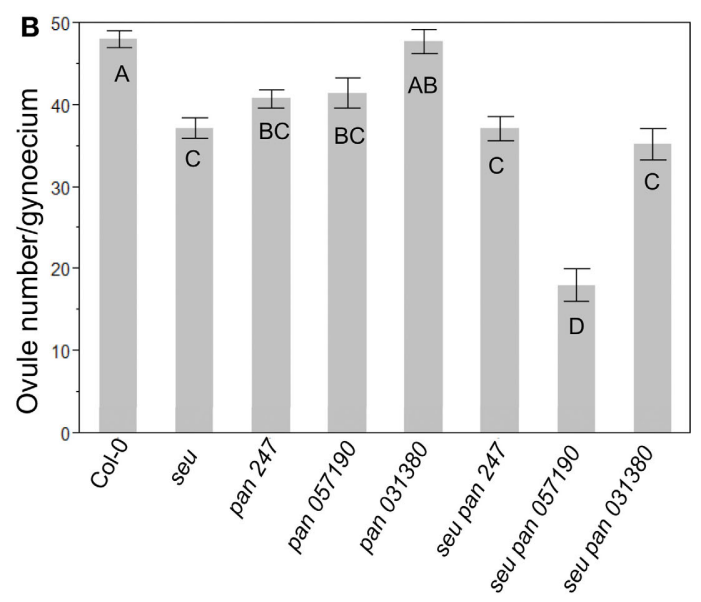

Genotype under long-day growth

C

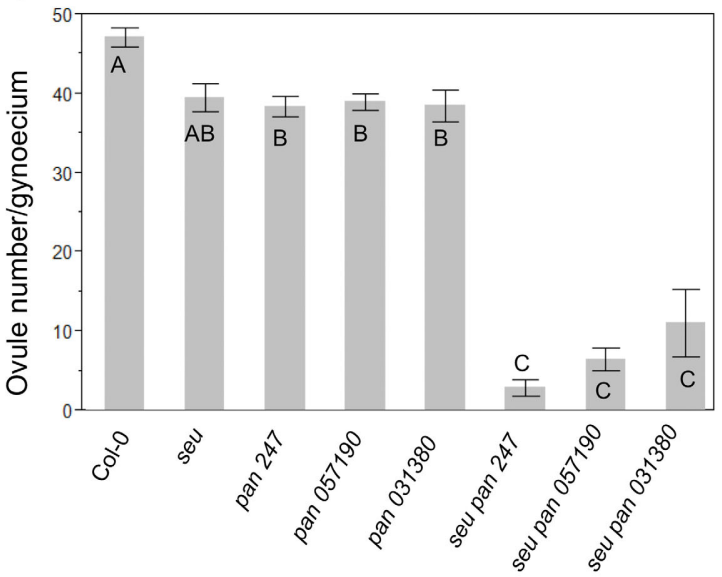

Genotype under short-day growth

FIGURE 1 | Ovule number is decreased in pan ant and seu pan double mutants. (A) Under long-day growth conditions pan ant double mutants displayed an enhanced loss of ovules relative to single mutant parents for all three pan alleles examined. (B) Under long-day growth conditions only the seu pan 057190 plants showed a statistical reduction in ovule number compared to single mutants parents. (C) Under short-day growth conditions, the seu pan double mutants displayed an enhanced loss of ovules relative to single mutant parents for all three pan alleles examined. Comparisons for statistical differences across genotypes were made via pair-wise mean testing and the Tukey HSD post-hoc test-different letters indicate statistically different categories. Each error bar is constructed using 1 standard error from the mean. mutants and the single mutant parents (Figure 1B). We again detected a slight reduction in ovule number in the pan single mutants relative to wild type, however this time the reduction was statistically significant in both the pan 057190 and the pan SAIL_247 alleles. The seu single mutant also conditioned a significant loss of ovules relative to Col-0. Furthermore, ovule loss in the seu pan double mutant was significantly enhanced by one of the three pan alleles (057190) that we tested under our long-day growth conditions (Figure 1B).

Short-day growing conditions have been previously shown to enhance the severity of mutant phenotypes of pan mutants (Maier et al., 2009, 2011). Under short-day conditions all three pan alleles displayed a statistically-significant reduction in ovule number relative to Col-0 grown under similar conditions (Figure 1C). Furthermore, all three alleles of the seu pan double mutant gynoecia exhibited an enhanced loss of ovules relative to either the pan or the seu single mutants. Thus, under the short-day growing conditions pan single mutants displayed a modest but significant reduction in ovule number relative to wild type, while ovule loss was enhanced in seu pan double mutants relative to the single mutants.

\section{pan MUTANT ALLELES CONDITION ENHANCED DISRUPTIONS OF GYNOECIAL MORPHOLOGY IN seu AND ant MUTANT BACKGROUNDS}

The wild type Arabidopsis gynoecium is composed of two carpels that are fused along the carpel margins. The fused margins of the carpels are situated within the medial portion of the gynoecium. The growth of the medial gynoecial domain is reduced in the seu ant mutant resulting in gynoecial splitting and a loss of ovule formation (Azhakanandam et al., 2008). Thus, we 
examined the pan single and seu pan and pan ant double mutant gynoecia for gynoecial splitting and other gross morphology disruptions. Alterations to the overall gynoecial morphology were evident under both long- and short-day conditions, but they were more pronounced in plants grown under short-day conditions (Figure 2).

Under long-day growth conditions, we evaluated gynoecia for both carpel splitting and carpel bending phenotypes employing a severity index from 1 to 4 (See Materials and Methods). We then used this severity index to generate a mean severity score for the comparison of genotypes of interest. Carpel bending and carpel splitting phenotypes were not observed in the Col-0 gynoecia that we assayed. Under the long-day growth conditions, the ant single and pan single mutants did display a mild degree of carpel splitting (Figure 3A). However, the pan ant double mutants displayed a statistically significant enhancement of carpel splitting compared to the single mutant gynoecia (Figures 2C, 3A). This is manifested by a greater proportion of double mutant gynoecia for which splitting was characterized as moderate or severe. Although seu single mutants displayed a mild degree of carpel splitting (Figure 2D), the carpel splitting phenotype was not enhanced in the seu pan double mutant under long-day conditions (Figure 2F).

Using a similar severity index we evaluated carpel bending. The seu pan 057190 showed statistically significant enhancement in carpel bending compared to the pan single mutant (seu single mutants rarely display a bending phenotype under long-day) (Figure 3B). The bending phenotype appears to be the result of the gynoecium consisting of only one carpel that fuses to itself (data not shown). These data suggest that PAN and SEU play a role in both promotion of medial domain development and in the proper formation of two carpels in whorl four.

Under short-day growing conditions the severity and penetrance of seu pan gynoecial defects were enhanced relative to the long-day conditions (Figures 2G-O). (We did not examine the development of the pan ant double mutants under the short-day growing conditions.) To analyze the seu pan phenotypes under short-day conditions we scored the gynoecia for the occurrence of four phenotypes; complete loss of ovules, carpel bending, severe loss of valves (based on external cell-type morphology), and indeterminate growth from internal gynoecial positions. We did not observe any of these phenotypes in the Col-0 plants and they were found infrequently (5\%) in seu or pan single mutants (Table 2). The seu pan double mutants, however, frequently displayed severe ovule loss, loss of the external valve tissue morphology, carpel bending, and/or indeterminacy phenotypes (Figures 2G-K; Table 2). In the Col-0 and single mutant gynoecia the surface morphology of the abaxial replum (ar) cells is distinct from that of the valve (v) cells (Figures $2 \mathbf{L}-\mathbf{M}$ ). Thus, these cell fates can be distinguished by the external cell surface morphology. In a subset of the seu pan gynoecia from short-day grown plants, the cells of the valve and abaxial replum could still be distinguished (Figure 2N). However, between 33 and 63\% (depending on the mutant pan allele) of the seu pan double mutants displayed a severe alteration in the morphology of the external valve cells (Figure 20). In these gynoecia we could not identify cells with the surface morphology that is indicative of valve cell identity.
Instead all of the external gynoecial cells appeared to resemble abaxial replum cells (ar-like in Figure 2O).

Other phenotypes observed in the seu pan double mutant under short-day growth conditions included five sepals, a reduction in petal size and number (typically two reduced petals per flower) and reduced production of pollen from anthers (data not shown). Additionally, the seu pan double mutant plants displayed an enhanced delay in the transition from vegetative to reproductive development as determined by counting the number of rosette leaves formed before bolting (Figure S1).

\section{FLORAL MERISTEM INDETERMINACY IS ENHANCED IN THE seu pan DOUBLE MUTANTS UNDER SHORT-DAY GROWING CONDITIONS}

In the wild type Arabidopsis flower, the floral meristem terminates after the formation of the gynoecium. AG is required to promote the termination of the floral meristem (floral determinacy) by repressing the expression of WUS, a stem cell maintenance gene within the floral meristem (Laux et al., 1996; Mayer et al., 1998; Parcy et al., 1998; Busch et al., 1999; Lohmann et al., 2001; Lenhard et al., 2002). We examined seu pan double mutants to determine the extent of floral indeterminacy under both long-day and short-day conditions. We characterized fifth whorl structures as an over-proliferation of cells at the base of the gynoecium (Figures 2F-K). These structures were typically enclosed within the gynoecial tube.

These fifth whorl structures were observed in $15 \%$ of seu pan 057190 and seu pan 247 double mutants in long-day tissues, but not seen in either single mutant. Under short-day conditions the presence of fifth whorl structures was significantly more frequent in seu pan plants compared to both the frequency in the single mutants as well as to the double mutants grown in long-day conditions (Table 2). The fifth whorl structures appeared larger and more elaborated under short-day conditions. This data suggests that both $P A N$ and SEU function to promote floral meristem determinacy and that this phenotype is more penetrant under the short-day growing conditions.

\section{WUS EXPRESSION AND INFLORESCENCE MERISTEM STRUCTURE ARE ALTERED IN seu pan DOUBLE MUTANT PLANTS}

The fifth whorl structures formed in the seu pan double mutants gynoecia were also examined for WUS expression as a marker for indeterminacy and a persistent functioning meristem. We occasionally were able to detect ectopic WUS expression in the fifth whorl structures (Figure 4B) suggesting that ectopic WUS expression may contribute to the formation of fifth whorl structures. However, we found additional examples of fifth whorl structures that did not express WUS (data not shown). Thus, although we were able to document cases of perdurant WUS expression, our data suggests that this ectopic expression is likely relatively short in duration and that WUS expression is not continuously maintained in the fifth whorl structures.

We also detected WUS expression in the center of the shoot apical meristem (SAM) and in early stage floral primordia (Figure 4). In Col-0, WUS is tightly expressed in a small number of cells in both the SAM and floral meristem (Laux et al., 1996; Mayer et al., 1998) (Figures 4D-H). In the seu pan mutant, the domain of WUS expression within both the SAM and the floral 

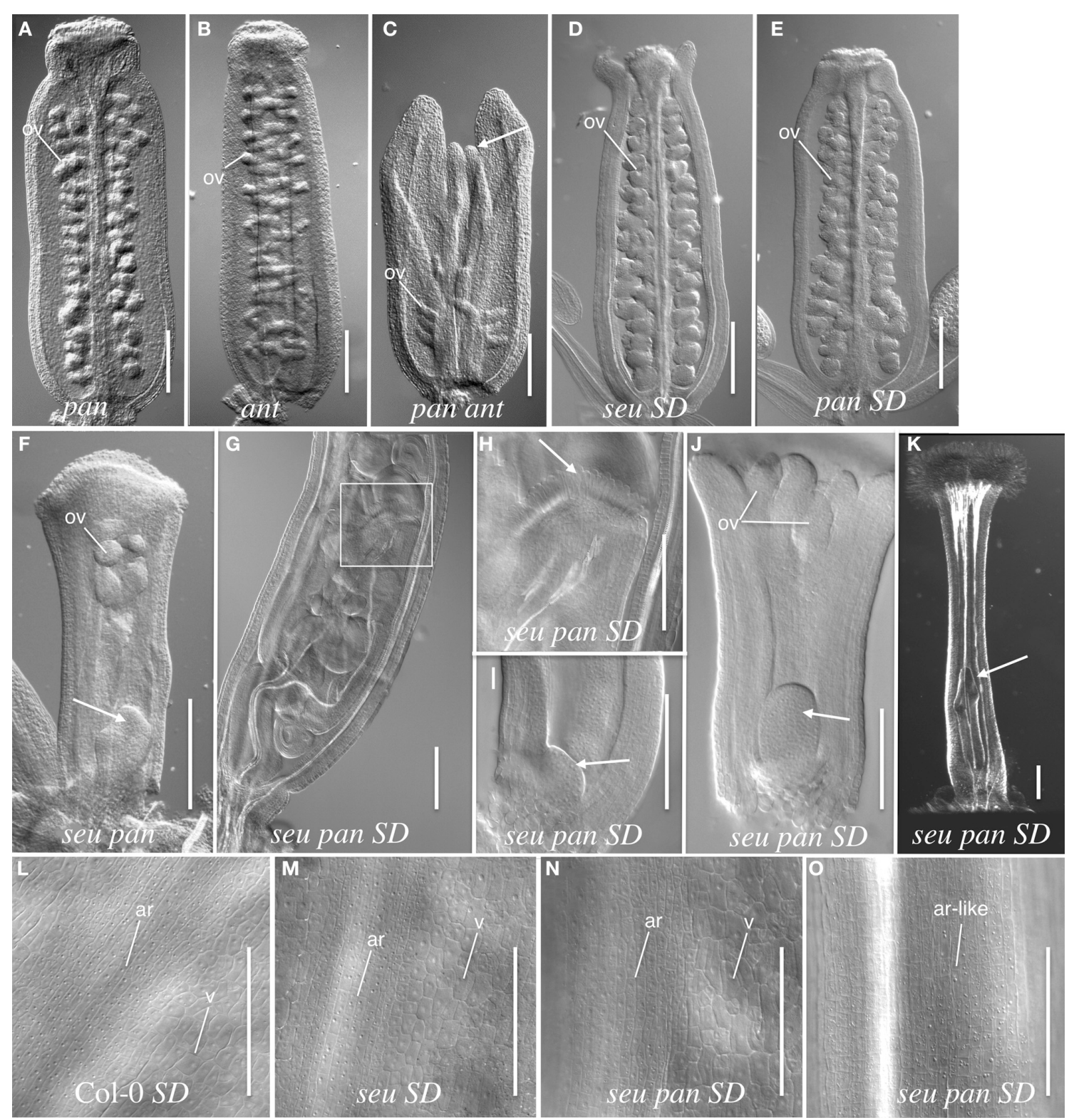

FIGURE 2 | Gynoecial and ovule phenotypes in pan ant and seu pan double mutants. (A) pan 057190 single mutant gynoecium. (B) ant single mutant gynoecium. (C) pan 057190 ant double mutant gynoecium displays reduced ovule number, a reduction in the growth of the medial domain (arrow) and enhanced splitting of the gynoecium. Arrow in panel (C) indicates the apical extent of the medial domain of the carpel. (D) seu single mutant gynoecium grown under short-day (SD) conditions shows slight splitting of the gynoecial apex. (E) SD-grown pan single mutant displays near wild type phenotype. (F) seu pan 057190 double mutant (long-day conditions) displays a "fifth whorl" structure inside the gynoecium (arrow). (G) SD-grown seu pan 057190 double mutant displays a well-developed "fifth whorl" structure inside the gynoecium. (H) A higher magnification image of the boxed area shown in panel (G). Arrow indicates the stigmatic tissue at the apex of second gynoecium developing within the primary gynoecium. (I) SD-grown seu pan 057190 double mutant (stage 8) arrow indicates early stage of fifth whorl structure. (J) SD-grown seu pan 057190 double mutant (stage 9) arrow indicates fifth whorl structure. (K) SD-grown seu pan 057190 double mutant displays a complete loss of ovule primordia, the loss of normal external valve cell surface morphology, and the presence of a "fifth whorl" structure (arrow). (L-O) epidermal cell morphology of external (abaxial) surface of the gynoecium. Distinctive cell surface morphology is observed in valve $(\mathrm{V})$ and abaxial replum (ar) regions in Col-0 wild type (L), seu single mutant (M) and a subset of seu pan double mutants (N). However, in severely disrupted seu pan double mutants $(\mathbf{O})$ the cell surface morphology of valve cells is not observed and all cells display an abaxial replum-like (ar-like) morphology. Scale bars in all panels are 200 microns, except for panels (H-J) where scale bars are 100 microns. ov, ovule; SD, Short-day growth conditions; ar, abaxial replum; v, valve. meristem appeared broader and more diffuse than it was in the wild type samples (Figures $4 \mathbf{I}-\mathbf{M}$ ). Although we did not quantify the size of the IFM, or observations of in situ sections showed instances where the size of the seu pan IFM was enlarged relative to the Col- 0 or single mutant parents (compare $4 \mathrm{D}$ to $4 \mathrm{I}$ ). In some of the seu pan inflorescence meristems the WUS expressing region was expanded and appeared to be punctuated as if several organizing centers had been formed within the potentially compound 


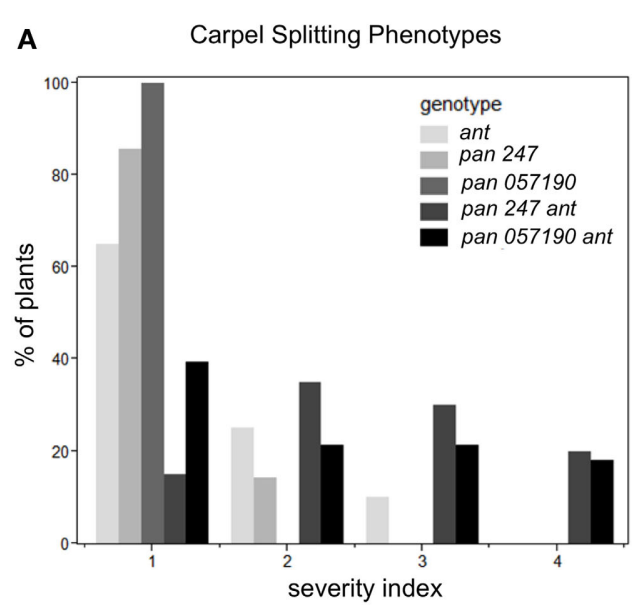

FIGURE 3 | Enhanced severity of carpel splitting in pan ant and carpel bending in seu pan double mutants under long-day growth conditions. (A) The pan ant double mutants showed a statistically more severe carpel splitting than the single mutant parents. (B) seu pan double mutant plants showed statistically more severe carpel bending than the single mutant
B Carpel Bending Phenotypes

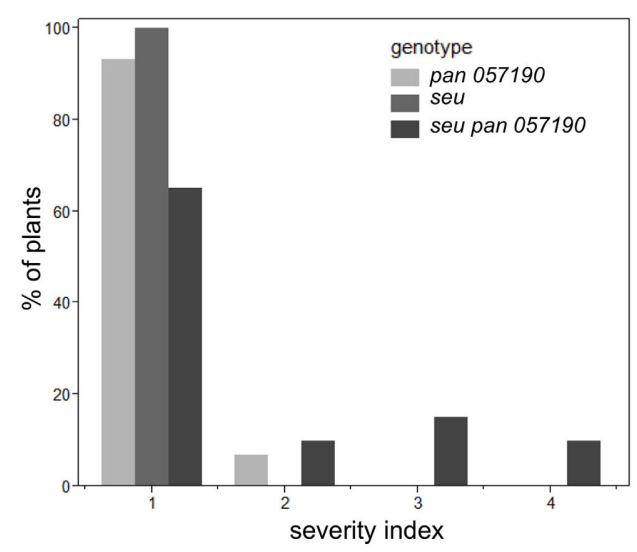

parents. Severity index for the carpel splitting: 1, no splitting; 2, mild splitting (flared tips or slight split); 3, moderate splitting (highly flared); 4 , severe or completely split. Severity index for carpel bending: 1 , no bending; 2 , slight bending; 3, moderate bending; 4, severe bending. Statistical analysis was conducted with a Student's $T$-test and $p$-values less than 0.05 .

Table 2 | Gynoecial disruption in short-day grown plants.

\begin{tabular}{|c|c|c|c|c|c|}
\hline Genotype & $\begin{array}{c}\text { Complete loss of } \\
\text { ovules (\%) }\end{array}$ & $\begin{array}{l}\text { Carpel bending } \\
(\%)\end{array}$ & $\begin{array}{l}\text { Loss of external valve } \\
\text { tissue morphology (\%) }\end{array}$ & $\begin{array}{l}\text { Fifth whorl structure } \\
\text { within the carpels (\%) }\end{array}$ & $\begin{array}{c}\text { Number of } \\
\text { gynoecia counted }\end{array}$ \\
\hline Col-0 & - & - & - & - & 18 \\
\hline Seu & - & 5 & - & - & 20 \\
\hline pan 057190 & - & - & - & 5 & 21 \\
\hline pan 247 & - & - & - & 5 & 20 \\
\hline seu pan 051790 & 35 & 33 & 33 & 71 & 31 \\
\hline seu pan 247 & 52 & 63 & 63 & 32 & 19 \\
\hline
\end{tabular}

Categorization of the significant gynoecial disruptions. Note: phenotypes are not mutually exclusive and thus percentages can add up to more than $100 \%$.

inflorescence meristem (Figure 4C; arrows). Thus, the disruption of WUS expression or accumulation in the IFM and early stage floral meristems as well as an ectopic persistence of expression within the floral meristem may contribute to the morphological disruptions observed in the seu pan mutant flowers.

\section{AGAMOUS IS MIS-EXPRESSED IN WHORL ONE OF THE seu pan DOUBLE MUTANT FLOWERS}

In light of the known role of $A G$ in regulating floral determinacy, and $S E U$ and $P A N$ acting as regulators of $A G$ expression, we examined $A G$ expression patterns in seu pan plants via in situ hybridization. A dominant negatively-acting $P A N-R D$ transgene, in which a transcriptional repression domain has been fused to the PAN coding sequences, has been shown to condition floral indeterminacy that was correlated with a reduction of $A G$ expression within whorl four (Das et al., 2009). We also sought to determine if the levels of $A G$ were reduced in whorl four in the pan seu double mutants. However, we could not detect a consistent reduction in the levels of $A G$ expression in whorl 4 under long-day or short-day growth conditions.
Somewhat unexpectedly, we frequently observed instances of ectopic $A G$ expression in seu pan double mutant whorl 1 organs (Figures 5D,F,H). Upon closer examination of the external cell morphology of floral organs from the seu pan flowers, we detected instances of chimeric organs in whorls one including partially petaloid and stamenoid organs (Figure 6). These partial homeotic organ transformations have been reported in the seu single mutant previously (Franks et al., 2002) but are rarely seen in the seu- 3 allele in the Col-0 background that we have used in this study (Pfluger and Zambryski, 2004). We found the $30 \%$ $(N=43)$ of the seu pan whorl one floral organs exhibited partial homeotic transformations based on the cell surface morphologies (Table 3). These homeotic transformations were not observed in the seu and pan single mutant parents under our growth conditions. Based on the organ type specific cell surface morphology, the seu pan whorl one organs appeared to be sepals that were partially converted to petals (Figure 6). The presence of cells with the classic petal cell morphology was most often observed on the adaxial and marginal portions of the sepals (Figures 6A-C). These data are consistent with $P A N$ acting in a partially redundant 


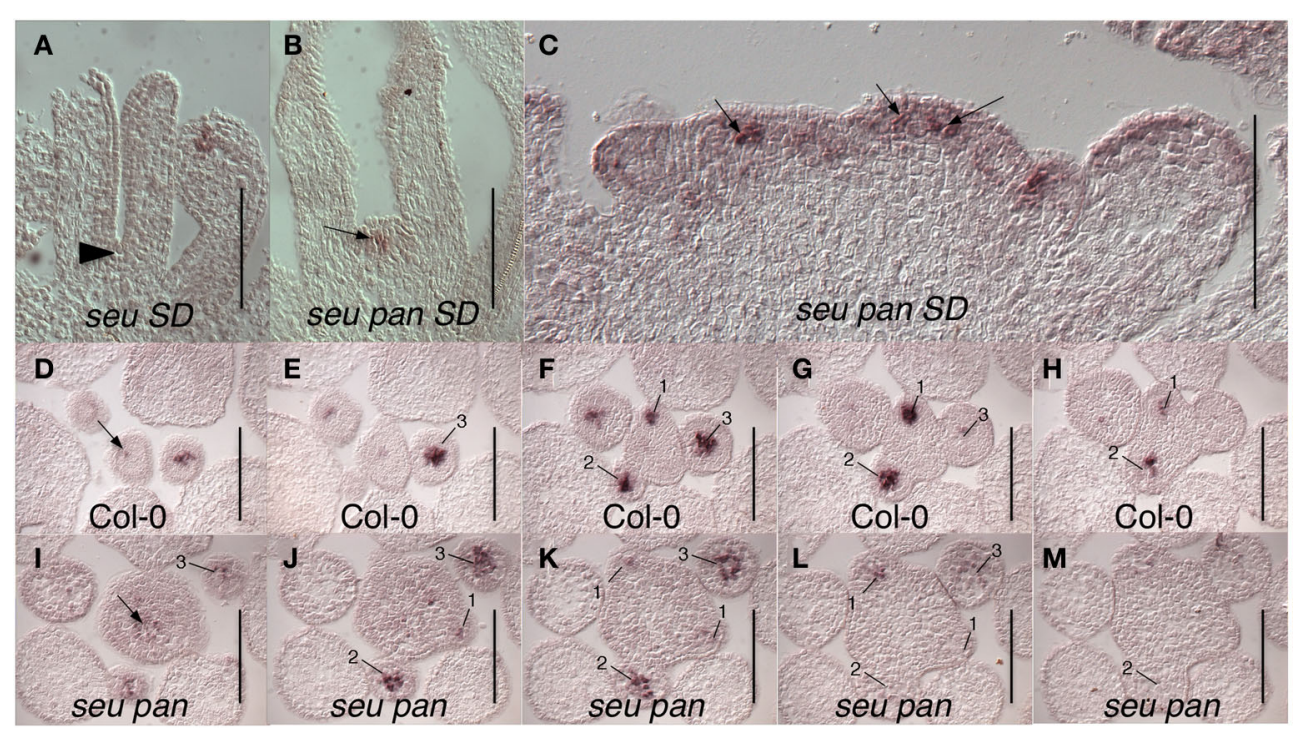

FIGURE 4 | WUS expression in seu pan double mutants. (A) No WUS expression is detected at the base of the stage 8 gynoecium (arrowhead) in this longitudinal section of a Col-0 flower. (B) WUS expression is detected in fifth whorl structure (arrow) at the base of the stage 8 seu pan gynoecium. (C) Longitudinal section of a fasciated inflorescence meristem (IFM) from seu pan double mutant where WUS expression appears in multiple foci (arrows) as well as diffusely throughout IFM. (D-M) Serial cross sections through Col-O (D-H) and seu pan (I-M) inflorescences. Within a given genotype each cross section is 8 microns below the preceding cross section. (D-H) WUS expression is detected in the organizing center of the IFM (arrow) and in central zones of stage 1-3 floral meristems (numbered). (I-M) In the seu pan double mutants, the region of WUS expression appears more diffuse and somewhat expanded, both in the INF (arrow) and in the developing floral meristems (numbered). Note also that the IFM is larger in the seu pan double mutant. Scale bars are 100 microns in all panels.

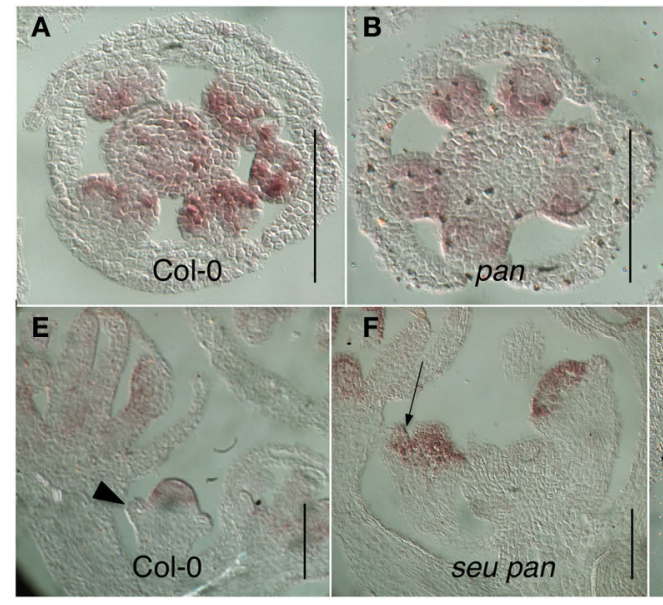

FIGURE 5 | Ectopic $A G$ expression in the seu pan double mutants. (A-D) Floral cross sections (E-H) Floral longitudinal sections. Arrowheads indicate sepals within which $A G$ expression is not detected. Arrows indicate sepals within which ectopic $A G$ expression

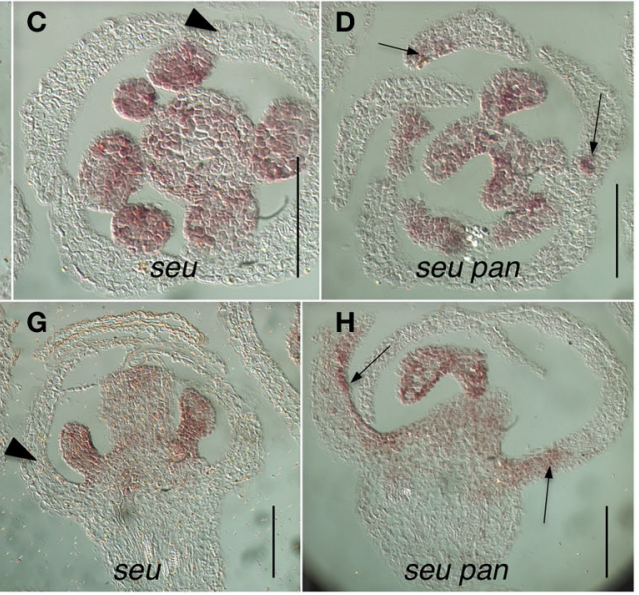

is detected. Ectopic expression of $A G$ is most strongly detected in the adaxial and marginal portions of the developing first whorl organs in the seu pan 057190 double mutants (panels $\mathbf{D , F}, \mathbf{H}$ ). Scale bars are 40 microns in length. fashion with $S E U$ during the repression of $A G$ in the developing sepals. As previous accounts of PAN expression (Chuang et al., 1999) did not report PAN expression in whorl one organs, we examined expression of PAN via in situ hybridization to look carefully at the developing whorl one organs. We detected expression of PAN in portions of the developing whorl one primordia in wild type floral buds during stages 3-6. This was chiefly confined to the adaxial and marginal portions of the developing sepals (Figures 6D-F). Thus, there is a good correlation between the expression domain of the PAN transcript in wild type and the presence of homeotic cell type transformation in the seu pan mutant. 


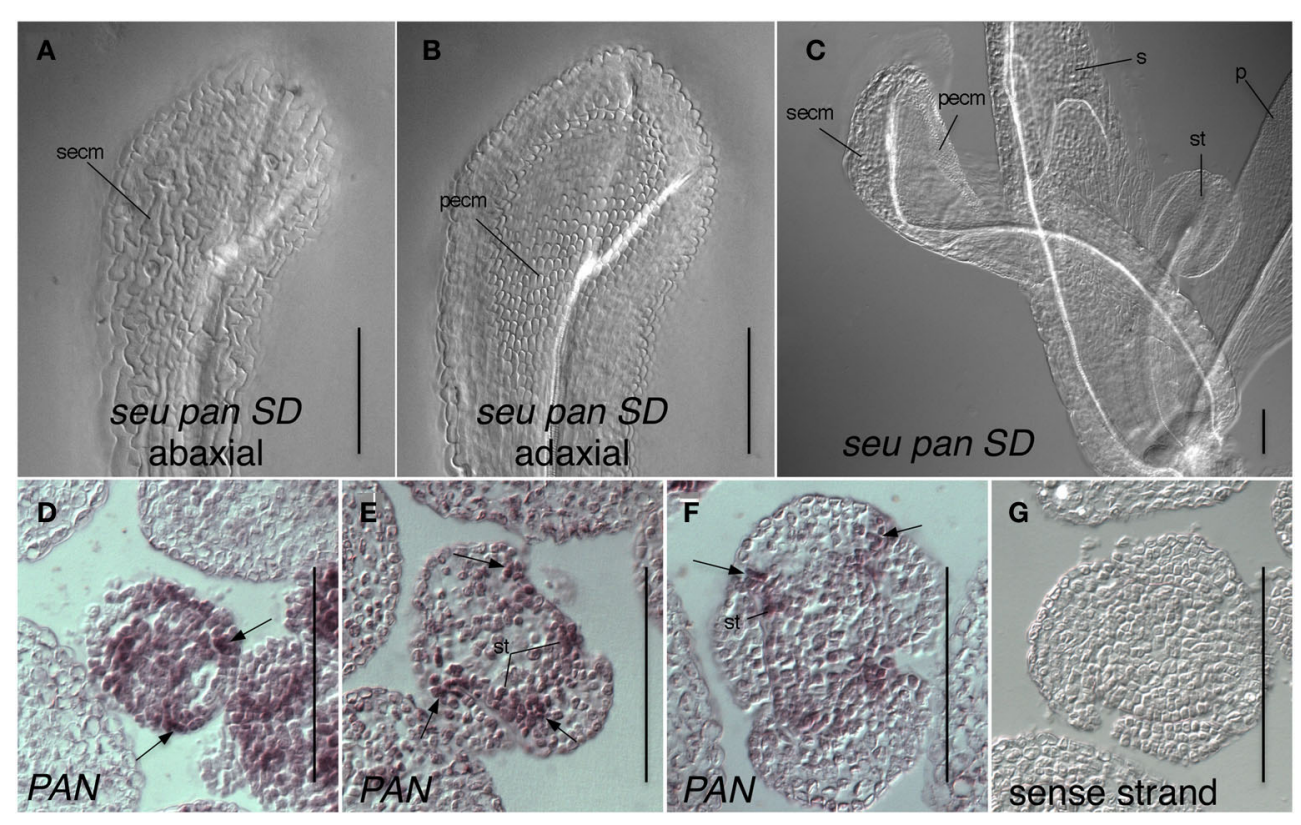

FIGURE 6 | Expression of PAN in adaxial portions of sepals is consistent with a role for $P A N$ in the repression of $A G$ and specification of organ identity. (A-C) Differential interference contrast optics microscopic image of chloral hydrate cleared tissue. (A) Abaxial surface of whorl one organ in seu pan short-day (SD)-grown flower displays cells with sepal epidermal cell morphology (secm). (B) Adaxial surface of same organ as in panel (A) displays petal epidermal cell morphology (pecm). (C) A seu pan flower displays a partial homeotic transformation of whorl one organ on adaxial surface as indicated by the presence of petal epidermal cell morphology (pecm). Morphologically normal petal (p), sepal (s), and stamen (st) are indicated. (D) Stage 3 floral cross section. PAN expression is detected in adaxial and marginal portions of developing sepals (arrows) as well as in stamen anlagen and floral meristem. (E,F) PAN expression is detected in adaxial and marginal portions of developing sepals (arrows) as well as in stamen primordia (st) in stage 5 (E) and stage 6 (F) floral cross sections. (G) sense strand control hybridization on stage 5 floral cross section. Scale bars are 100 microns in all panels.
Table 3 | Chimeric floral organs in seu pan double mutants under short-day conditions.

\begin{tabular}{lcc}
\hline Genotype & \% Chimeric sepals & $\%$ Chimeric petals \\
\hline Col-0 & $0(N=19)$ & $0(N=8)$ \\
seu-3 & $0(N=32)$ & $0(N=26)$ \\
pan 057190 & $0(N=23)$ & $0(N=11)$ \\
seu-3 pan 057190 & $30(N=43)$ & $0(N=11)$ \\
\hline
\end{tabular}

\section{DISCUSSION}

\section{ROLE OF PAN IN GYNOECIAL MEDIAL DOMAIN DEVELOPMENT}

The enhancement of gynoecial defects observed in the seu pan and pan ant double mutants relative to the single mutant parents indicates (1) that PAN plays a role in the development of the medial domain of the gynoecium and that (2) this role is revealed when the activity of $S E U$ or ANT is compromised. The dependence of the phenotype on the loss of function of SEU or ANT suggests that the function of PAN during gynoecial development is partially overlapping with that ofSEU and ANT. The defects of the seu pan double mutant are similar to, but distinct from the ant pan double mutant, indicating a differential sharing of functions between these three genes.

The defects observed in the pan ant double mutants include an enhanced loss of ovules and enhanced splitting of the gynoecial tube relative to the single mutant parents (Figures 1A, 3A).
Both of these we interpret as the result of a reduced growth of the medial domain of the gynoecium. In the pan ant double mutants the medial domain does not grow to the same extent as the neighboring lateral domains (Figure 2C). This may result in the failure of the gynoecial tube to fuse completely, as well as contribute to a loss of ovule primordia.

The seu pan double mutant also displays an enhanced loss of ovules, although this is not as severe as that observed in the pan ant double mutant. Gynoecial splitting was not enhanced in the seu pan double mutants. The severity of carpel bending was enhanced in the seu pan double mutants relative to the parental genotypes. The enhanced curving of the gynoecial tube resulted from the loss of one of the two component carpels and the fusion of the remaining carpel upon itself (data not shown). This data suggests that SEU and PAN share a function in the regulation of carpel number. In the most severely affected seu pan double mutants, there is a loss of the characteristic morphology of the abaxial valve epidermal cells and these cells develop as cells that are morphologically similar to abaxial replum cells (Figures $2 \mathrm{~L}-\mathbf{O}$ ) suggesting that patterning along the medial lateral extent of the gynoecium may be affected. The analysis of additional markers of the medial and lateral domains in the seu pan double mutant would help to determine if there is an alteration in medial/lateral patterning events in the seu pan double mutant. 
PAN is expressed within the adaxial portions of the medial domain and in the developing ovule primordia (Chuang et al., 1999; Wynn et al., 2011) and thus may directly regulate genes within the medial domain that support medial domain development. Alternatively, as PAN is also expressed within the vegetative shoot apex, as well as the IFM and developing floral meristems (Chuang et al., 1999; Fulcher and Sablowski, 2009; Maier et al., 2009) (Figure 6), the effects of PAN on earlier stage floral meristems or perhaps the IFM may lead to later effects on the development of ovules from the medial domain.

Previous analyses of pan ettin (ett) and pan tousled ( $t$ sl) double mutants indicated that PAN also shares overlapping functional roles with TSL and ETT during medial domain development (Roe et al., 1997; Sessions et al., 1997). The carpels of the pan tsl double mutant gynoecia are completely unfused and serrated at their margins (Roe et al., 1997). The CMM-derived tissues are also significantly reduced in these gynoecia and very few ovules develop. Similarly Sessions et al. reported a synergistic loss of ovule and placental development in the pan ett double mutant (Sessions et al., 1997). Thus, a variety of non-additive genetic interactions affecting gynoecial development have been described for the seu, lug, pan, ant, ett, and tsl higher order mutants (Roe et al., 1997; Sessions et al., 1997; Liu et al., 2000; Franks et al., 2002; Pfluger and Zambryski, 2004; Azhakanandam et al., 2008).

\section{ROLE OF SEU AND PAN IN FLORAL MERISTEM DETERMINACY}

$P A N$ has been previously shown to function in the termination of the floral meristem and to function as an activator of $A G$ (Das et al., 2009; Maier et al., 2009). The direct binding of PAN to conserved regulatory elements within the $A G$ second intron and the functional importance of these elements in generating the $A G$ expression pattern strongly suggests that PAN directly functions as an activator of $A G$ expression. Consistent with this Maier et al. reported a reduction in $A G$ transcript in the pan single mutant, but only when this mutant was grown under short-day conditions (Maier et al., 2009). Das et al. did not detect a reduction in the pan single mutant, but did observe a reduction of $A G$ expression within whorl 4 in plants that carried a dominant negative $P A N-R D$ construct in which $P A N$ is fused to a strong transcriptional repressor domain (Das et al., 2009). These results suggest that the function of redundant regulatory elements within the $A G$ second intron (Sieburth and Meyerowitz, 1997; Bomblies et al., 1999; Deyholos and Sieburth, 2000) and of redundant bZIP family members (Das et al., 2009; Maier et al., 2009) may reduce the phenotypic consequences of the loss of PAN function on $A G$ expression. Das et al. and Maier et al. both reported ectopic expression of WUS in fifth whorl structures in pan single mutants. However, they did not report alterations to WUS expression patterns at earlier stages of floral development. We also did not observe altered WUS expression in pan single mutants. However, we observed alterations of the WUS expression patterns that are evident in the seu pan double mutant, particularly when grown under short-day conditions. In these cases WUS expression was often more diffusely localized within the IFM and the developing floral meristems. Additionally we observed instances of perdurant WUS expression within the developing fifth whorl structures. Thus, a deregulation of WUS expression or localization is likely to contribute to the indeterminacy phenotypes observed in the seu pan double mutants.

As $P A N$ functions as an activator of $A G$ transcription, and $A G$ as a repressor of WUS expression, this deregulation of WUS may be caused by a reduction in $A G$ transcription or by posttranscriptional regulation of $A G$ activity or both. We did not detect a consistent reduction in the levels of $A G$ expression in either the pan single mutant or the seu pan double mutant under either long-day or short-day growth conditions. Yet the fifth whorl indeterminacy phenotypes were clearly enhanced in the seu pan double mutant under the short-day growing conditions. It is possible that the in situ hybridization assay is not sensitive enough to detect modest, yet biologically-significant reductions in $A G$ transcript. Alternatively, as SEU can physically interact with several MADS domain-containing proteins that dimerize with AG (e.g., AP1, SEP3, SVP, and AGL24) (Gregis et al., 2006; Sridhar et al., 2006; Smaczniak et al., 2012), we propose that the SEU protein may regulate the ability of AG to function via physical interactions with these MADS domain proteins. Thus, the ability of the AG protein to repress WUS expression and thus bring about floral stem cell termination may be compromised in the seu mutant background. This would be consistent with the ectopic persistence of WUS expression observed in the seu pan fifth whorl structures. It also might contribute to the fasciation defects we observed and to the expansion of the WUS expression domain in the IFM and floral meristems.

\section{WHORL SPECIFIC ACTION OF PAN AND SEU IN THE REPRESSION OF AG EXPRESSION AND SPECIFICATION OF ORGAN IDENTITY}

$S E U$ functions as a transcriptional adaptor required for the repression of $A G$ transcription within whorls 1 and 2 (Franks et al., 2002; Gregis et al., 2006; Sridhar et al., 2006; Gonzalez et al., 2007). SEU forms a complex with several MADS domaincontaining proteins and the transcriptional co-repressor LUG to bind to the second intron sequences of $A G$. This brings about repression via histone deacetlyation (Sridhar et al., 2006; Gonzalez et al., 2007). The loss of PAN activity in the seu pan double mutant enhances the de-repression of $A G$ in whorl 1 structures and leads to the partial homeotic transformation of sepals (Figures 5, 6). Thus, we suggest that $P A N$ functions in the repression of $A G$ in whorl 1, a function that is partially overlapping with SEU. As we have detected PAN transcript in the adaxial and marginal portions of the developing sepals, a direct role for PAN in the repression of $A G$ is plausible.

We have been unable to demonstrate a physical interaction between SEU and PAN in a yeast two hybrid assay (data not shown). However, both PAN, as well as SEU-containing complexes have been shown to bind directly to the DNA regulatory elements found within the $A G$ second intron (Sridhar et al., 2004, 2006; Das et al., 2009; Maier et al., 2009). Thus, we favor a model in which both SEU and PAN via direct interaction with the $A G$ second intron bring about the repression of $A G$ expression within developing whorl one organs. The action of additional redundant regulators of $A G$ repression (AP2, and SEUSS-LIKE family members) (See for review Liu and Mara, 2010) likely buffers the extent of $A G$ de-repression that is observed in the seu pan double mutant. Furthermore, the mis-specification of 
petal cell identity in the whorl 1 structures suggests that Bclass genes required for petal identity specification (e.g., $P I$ and $A P 3)$ are also likely to be de-repressed in the seu pan double mutant, although we have not yet confirmed this with in situ hybridization experiments. Ectopic expression of B-class genes in whorl one organs could be caused by ectopic $A G$ expression. Previously lug alleles were shown to condition the partial transformation of whorl one organs to petaloid and stamenoid chimeric organs and ectopic expressions of the B-class genes PISTILLATA (PI) and APETALA3 (AP3) were detected in developing whorl one structures (Liu and Meyerowitz, 1995). Liu and Meyerowitz demonstrated that the petaloid characteristics of the whorl one organs in lug mutants were dependent on ectopic $A G$ expression (i.e., the petaloid characteristics were not observed in the lug ag double mutants). They propose that the ectopic $A G$ brings about an ectopic expression of the BClass genes and this is consistent with the identification of $P I$ and $A P 3$ as targets of $A G$ regulation by Gomez-Mena et al. (2005).

Our data suggests that $S E U$ and PAN function in a whorl specific fashion in the regulation of $A G$ transcription or activity. $S E U$ and $P A N$ activities are required for efficient repression of $A G$ in whorl 1 while their activities are required for efficient activation of $A G$ function in whorl four. We propose that the differential action of these proteins is due to whorl specific co-factors or posttranscriptional modifications. The identity of these whorl specific modifiers remains to be elucidated.

\section{RELATIONSHIP BETWEEN FLORAL MERISTEM TERMINATION AND CMM DEVELOPMENT}

Zuniga-Mayo et al. previously suggested a relationship between the proper termination of the floral meristem and the subsequent development of the CMM (Zuniga-Mayo et al., 2012).

This was based on their analysis of jaiba crabs claw double mutants that display a loss of floral determinacy as well as defects in the development the CMM. Our investigation of the seu pan double mutant further supports this possibility. When ovules develop in the seu pan double mutants, they arise at apical positions within the gynoecium, and thus at a distance from the basally-located fifth whorl structures. Thus, if the floral meristem fails to properly terminate, the cells furthest from the perdurant meristem are more likely to form ovules than those closer to the meristem. This could suggest a gradient of an inhibitor from the floral meristem. However, it is equally likely that a temporal effect explains the difference. As the gynoecium grows from the apex, cells that divided temporally later in development will also be found in more apical positions. Thus, the decay over time of any inhibitory effect of the floral meristem might also result in the formation of ovules only at the apex of the seu pan double mutants.

\section{AUTHOR CONTRIBUTIONS}

April N. Wynn and Robert G. Franks: conceived and designed the experiments, analyzed the data, and wrote the paper; April N. Wynn, Andrew A. Seaman, Ashley L. Jones and Robert G. Franks: Performed the experiments.

\section{ACKNOWLEDGMENTS}

We acknowledge support for this research from the National Science Foundation (NSF grants IOS \#0821896 and IOS \#1355019). We thank the Arabidopsis Biological Resource Center for DNA clones and seed stocks.

\section{SUPPLEMENTARY MATERIAL}

The Supplementary Material for this article can be found online at: http://www.frontiersin.org/journal/10.3389/fpls.2014.00130/ abstract

Figure S1 | Short-day growth conditions reveal a floral transition delay in seu pan $\mathbf{0 5 7 1 9 0}$ double mutants Time to floral transition (in number of rosette leaves produced) indicates that both the seu single mutants and the seu pan double mutants have a delay in the transition to flowering. The seu pan plants are significantly more delayed than the seu single mutants. Comparisons for statistical differences across genotypes were made via pair-wise mean testing and the Tukey HSD post-hoc test-different letters indicate statistically different categories. Each error bar is constructed using 1 standard error from the mean. pan mutant alleles enhance the floral transition delay observed in seu single mutants. When examining seu pan plants grown in short-day conditions it was apparent that the seu pan double mutant plants were slower to transition to the reproductive growth phase. To quantify this delay, we counted the number of rosette leaves produced before the plants transition to a reproductive growth phase. The reproductive growth phase is characterized by the formation of cauline leaves and internode elongation. Under the short-day growing conditions the Col- 0 plants produce on average $40.8 \pm 4.7$ rosette leaves before transition to a reproductive growth phase (Figure S1). pan mutants show no statistically significant difference when compared to Col-0 $(43.2 \pm 4.5$ leaves). In contrast seu mutants exhibit a statistically significant delay in flowering relative to Col-0, producing $50.5 \pm 4.0$ leaves prior to bolting. Mutations in SEU also caused a delay in the floral transition in long-day growth conditions (Wynn and Franks, unpublished). When we examined the seu pan double mutants we observed that they were significantly delayed, relative to the single mutants, producing on average $60.4 \pm 5.1$ leaves before the transition. These results suggest that both PAN and SEU function to promote the transition to reproductive growth phase under short-day growing conditions.

\section{REFERENCES}

Alonso, J. M., Stepanova, A. N., Leisse, T. J., Kim, C. J., Chen, H., Shinn, P., et al. (2003). Genome-wide insertional mutagenesis of Arabidopsis thaliana. Science 301, 653-657. doi: 10.1126/science.1086391

Azhakanandam, S., Nole-Wilson, S., Bao, F., and Franks, R. G. (2008). SEUSS and AINTEGUMENTA mediate patterning and ovule initiation during gynoecium medial domain development. Plant Physiol. 146, 1165-1181. doi: 10.1104/pp.107.114751

Bomblies, K., Dagenais, N., and Weigel, D. (1999). Redundant enhancers mediate transcriptional repression of AGAMOUS by APETALA2. Dev. Biol. 216, 260-264. doi: 10.1006/dbio.1999.9504

Bowman, J. L., Baum, S. F., Eshed, Y., Putterill, J., and Alvarez, J. (1999). Molecular genetics of gynoecium development in Arabidopsis. Curr. Top. Dev. Biol. 45, 155-205. doi: 10.1016/S0070-2153(08)60316-6

Bowman, J. L., Smyth, D. R., and Meyerowitz, E. M. (1989). Genes directing flower development in Arabidopsis. Plant Cell 1,37-52. doi: 10.1105/tpc.1.1.37

Bowman, J. L., Smyth, D. R., and Meyerowitz, E. M. (1991). Genetic interactions among floral homeotic genes of Arabidopsis. Development 112, 1-20.

Bowman, J. L., Smyth, D. R., and Meyerowitz, E. M. (2012). The ABC model of flower development: then and now. Development 139, 4095-4098. doi: 10.1242/dev.083972 
Busch, M. A., Bomblies, K., and Weigel, D. (1999). Activation of a floral homeotic gene in Arabidopsis. Science 285, 585-587. doi: 10.1126/science.285.5427.585

Chuang, C. F., Running, M. P., Williams, R. W., and Meyerowitz, E. M. (1999). The PERIANTHIA gene encodes a bZIP protein involved in the determination of floral organ number in Arabidopsis thaliana. Genes Dev. 13, 334-344. doi: 10.1101/gad.13.3.334

Coen, E. S., and Meyerowitz, E. M. (1991). The war of the whorls: genetic interactions controlling flower development. Nature 353, 31-37. doi: $10.1038 / 353031 \mathrm{a} 0$

Das, P., Ito, T., Wellmer, F., Vernoux, T., Dedieu, A., Traas, J., et al. (2009). Floral stem cell termination involves the direct regulation of AGAMOUS by PERIANTHIA. Development 136, 1605-1611. doi: 10.1242/dev.035436

Deyholos, M. K., and Sieburth, L. E. (2000). Separable whorl-specific expression and negative regulation by enhancer elements within the AGAMOUS second intron. Plant Cell 12, 1799-1810. doi: 10.2307/3871193

Drews, G. N., Bowman, J. L., and Meyerowitz, E. M. (1991). Negative regulation of the Arabidopsis homeotic gene AGAMOUS by the APETALA2 product. Cell 65, 991-1002. doi: 10.1016/0092-8674(91)90551-9

Elliott, R. C., Betzner, A. S., Huttner, E., Oakes, M. P., Tucker, W. Q., Gerentes, D., et al. (1996). AINTEGUMENTA, an APETALA2-like gene of Arabidopsis with pleiotropic roles in ovule development and floral organ growth. Plant Cell 8, 155-168. doi: 10.2307/3870261

Franks, R. G., Wang, C., Levin, J. Z., and Liu, Z. (2002). SEUSS, a member of a novel family of plant regulatory proteins, represses floral homeotic gene expression with LEUNIG. Development 129, 253-263.

Fulcher, N., and Sablowski, R. (2009). Hypersensitivity to DNA damage in plant stem cell niches. Proc. Natl. Acad. Sci. U.S.A. 106, 20984-20988. doi: 10.1073/pnas.0909218106

Gomez-Mena, C., de Folter, S., Costa, M. M. R., Angenent, G. C., and Sablowski, R. (2005). Transcriptional program controlled by the floral homeotic gene AGAMOUS during early organogenesis. Development 132, 429-438. doi: 10.1242/dev.01600

Gonzalez, D., Bowen, A. J., Carroll, T. S., and Conlan, R. S. (2007). The transcription corepressor LEUNIG interacts with the histone deacetylase HDA19 and mediator components MED14 (SWP) and CDK8 (HEN3) to repress transcription. Mol. Cell. Biol. 27, 5306-5315. doi: 10.1128/MCB.01912-06

Gregis, V., Sessa, A., Colombo, L., and Kater, M. M. (2006). AGL24, SHORT VEGETATIVE PHASE, and APETALA1 redundantly control AGAMOUS druing early stages of floweing development in Arabidopsis. Plant Cell 18, 1373-1382. doi: 10.1105/tpc.106.041798

Gregis, V., Sessa, A., Dorca-Fornell, C., and Kater, M. M. (2009). The Arabidopsis floral meristem identity genes AP1, AGL24 and SVP directly repress class B and C floral homeotic genes. Plant J. 60, 626-637. doi: 10.1111/j.1365313X.2009.03985.x

Hill, J. P., and Lord, E. M. (1988). Floral Development in Arabidopsis thaliana: a comparison of the wild type and the homeotic pistillata mutant. Can. J. Bot. 67, 2922-2936. doi: 10.1139/b89-375

Hurst, H. C. (1995). Transcription factors 1: bZIP proteins. Protein Profile 2, 101-168.

Klucher, K. M., Chow, H., Reiser, L., and Fischer, R. L. (1996). The AINTEGUMENTA gene of Arabidopsis required for ovule and female gametophyte development is related to the floral homeotic gene APETALA2. Plant Cell 8, 137-153. doi: 10.1105/tpc.8.2.137

Krizek, B. A., and Eaddy, M. (2012). AINTEGUMENTA-LIKE6 regulates cellular differentiation in flowers. Plant Mol. Biol. 78, 199-209. doi: 10.1007/s11103011-9844-3

Laux, T., Mayer, K. F., Berger, J., and Jurgens, G. (1996). The WUSCHEL gene is required for shoot and floral meristem integrity in Arabidopsis. Development 122, 87-96.

Lenhard, M., Bohnert, A., Jurgens, G., and Laux, T. (2001). Termination of stem cell maintenance in Arabidopsis floral meristems by interactions between WUSCHEL and AGAMOUS. Cell 105, 805-814. doi: 10.1016/S00928674(01)00390-7

Lenhard, M., Jurgens, G., and Laux, T. (2002). The WUSCHEL and SHOOTMERISTEMLESS genes fulfil complementary roles in Arabidopsis shoot meristem regulation. Development 129, 3195-3206.

Liu, Z. C., and Mara, C. (2010). Regulatory mechanisms for floral homeotic gene expression. Semin. Cell Dev. Biol. 21, 80-86. doi: 10.1016/J.Semcdb.2009. 11.012
Liu, Z., Franks, R. G., and Klink, V. P. (2000). Regulation of gynoecium marginal tissue formation by LEUNIG and AINTEGUMENTA. Plant Cell 12, 1879-1892. doi: $10.2307 / 3871199$

Liu, Z., and Meyerowitz, E. M. (1995). LEUNIG regulates AGAMOUS expression in Arabidopsis flowers. Development 121, 975-991.

Lohmann, J. U., Hong, R. L., Hobe, M., Busch, M. A., Parcy, F., Simon, R., et al. (2001). A molecular link between stem cell regulation and floral patterning in Arabidopsis. Cell 105, 793-803. doi: 10.1016/S0092-8674(01)00384-1

Maier, A. T., Stehling-Sun, S., Offenburger, S. L., and Lohmann, J. U. (2011). The bZIP transcription factor PERIANTHIA: a multifunctional hub for meristem control. Front. Plant Sci. 2:79. doi: 10.3389/fpls.2011.00079

Maier, A. T., Stehling-Sun, S., Wollmann, H., Demar, M., Hong, R. L., Haubeiss, S., et al. (2009). Dual roles of the bZIP transcription factor PERIANTHIA in the control of floral architecture and homeotic gene expression. Development 136, 1613-1620. doi: 10.1242/dev.033647

Mayer, K. F., Schoof, H., Haecker, A., Lenhard, M., Jurgens, G., and Laux, T. (1998). Role of WUSCHEL in regulating stem cell fate in the Arabidopsis shoot meristem. Cell 95, 805-815. doi: 10.1016/S0092-8674(00)81703-1

McElver, J., Tzafrir, I., Aux, G., Rogers, R., Ashby, C., Smith, K., et al. (2001). Insertional mutagenesis of genes required for seed development in Arabidopsis thaliana. Genetics 159, 1751-1763.

Meyerowitz, E. M. (1997). Genetic control of cell division patterns in developing plants. Cell 88, 299-308. doi: 10.1016/S0092-8674(00)81868-1

Meyerowitz, E. M., Bowman, J. L., Brockman, L. L., Drews, G. N., Jack, T., Sieburth, L. E., et al. (1991). A genetic and molecular model for flower development in Arabidopsis thaliana. Dev. Suppl. 1, 157-167.

Mizukami, Y., and Fischer, R. L. (2000). Plant organ size control: AINTEGUMENTA regulates growth and cell numbers during organogenesis. Proc. Natl. Acad. Sci. U.S.A. 97, 942-947. doi: 10.1073/pnas.97.2.942

Nole-Wilson, S., and Krizek, B. A. (2000). DNA binding properties of the Arabidopsis floral development protein AINTEGUMENTA. Nucleic Acids Res. 28, 4076-4082. doi: 10.1093/nar/28.21.4076

Parcy, F., Nilsson, O., Busch, M. A., Lee, I., and Weigel, D. (1998). A genetic framework for floral patterning. Nature 395, 561-566. doi: 10.1038/26903

Pfluger, J., and Zambryski, P. (2004). The role of SEUSS in auxin response and floral organ patterning. Development 131, 4697-4707. doi: 10.1242/dev.01306

Reyes-Olalde, J. I., Zuniga-Mayo, V. M., Chavez Montes, R. A., Marsch-Martinez, N., and de Folter, S. (2013). Inside the gynoecium: at the carpel margin. Trends Plant Sci. 18, 644-655. doi: 10.1016/j.tplants.2013.08.002

Roe, J. L., Nemhauser, J. L., and Zambryski, P. C. (1997). TOUSLED participates in apical tissue formation during gynoecium development in Arabidopsis. Plant Cell 9, 335-353. doi: 10.1105/tpc.9.3.335

Running, M. P., and Meyerowitz, E. M. (1996). Mutations in the PERIANTHIA gene of Arabidopsis specifically alter floral organ number and initiation pattern. Development 122, 1261-1269.

Sablowski, R. (2007). Flowering and determinacy in Arabidopsis. J. Exp. Bot. 58, 899-907. doi: 10.1093/jxb/erm002

Sessions, A., Burke, E., Presting, G., Aux, G., McElver, J., Patton, D., et al. (2002). A high-throughput Arabidopsis reverse genetics system. Plant Cell 14, 2985-2994. doi: 10.1105/tpc.004630

Sessions, A., Nemhauser, J. L., McColl, A., Roe, J. L., Feldmann, K. A., and Zambryski, P. C. (1997). ETTIN patterns the Arabidopsis floral meristem and reproductive organs. Development 124, 4481-4491.

Sieburth, L. E., and Meyerowitz, E. M. (1997). Molecular dissection of the AGAMOUS control region shows that cis elements for spatial regulation are located intragenically. Plant Cell 9, 355-365. doi: 10.2307/3870487

Smaczniak, C., Immink, R. G., Muino, J. M., Blanvillain, R., Busscher, M., BusscherLange, J., et al. (2012). Characterization of MADS-domain transcription factor complexes in Arabidopsis flower development. Proc. Natl. Acad. Sci. U.S.A. 109, 1560-1565. doi: 10.1073/pnas.1112871109

Sridhar, V. V., Surendrarao, A., Gonzalez, D., Conlan, R. S., and Liu, Z. (2004). Transcriptional repression of target genes by LEUNIG and SEUSS, two interacting regulatory proteins for Arabidopsis flower development. Proc. Natl. Acad. Sci. U.S.A. 101, 11494-11499. doi: 10.1073/pnas.0403055101

Sridhar, V. V., Surendrarao, A., and Liu, Z. (2006). APETALA1 and SEPALLATA3 interact with SEUSS to mediate transcription repression during flower development. Development 133, 3159-3166. doi: 10.1242/dev.02498

Vaughn, J. G. (1955). The morphology and growth of the vegetative and reprodictive apices of Arabidopsis thaliana (L.) Heynh., Capsella bursa-pastoris (L.) 
Medic. and Anagallis arvensis (L.). J. Linn. Soc. Lond. Bot. 55, 279-301. doi: 10.1111/j.1095-8339.1955.tb00014.x

Weigel, D., and Meyerowitz, E. M. (1993). Activation of floral homeotic genes in Arabidopsis. Science 261, 1723-1726. doi: 10.1126/science.261.5129.1723

Wynn, A. N., Rueschhoff, E. E., and Franks, R. G. (2011). Transcriptomic characterization of a synergistic genetic interaction during carpel margin meristem development in Arabidopsis thaliana. PLoS ONE 6:e26231. doi: 10.1371/journal.pone.0026231

Yamada, K., Lim, J., Dale, J. M., Chen, H., Shinn, P., Palm, C. J., et al. (2003). Empirical analysis of transcriptional activity in the Arabidopsis genome. Science 302, 842-846. doi: 10.1126/science. 1088305

Yanofsky, M. F., Ma, H., Bowman, J. L., Drews, G. N., Feldmann, K. A., and Meyerowitz, E. M. (1990). The protein encoded by the Arabidopsis homeotic gene AGAMOUS resembles transcription factors. Nature 346, 35-39. doi: $10.1038 / 346035 \mathrm{a} 0$

Zuniga-Mayo, V. M., Marsch-Martinez, N., and de Folter, S. (2012). JAIBA, a class-II HD-ZIP transcription factor involved in the regulation of meristematic activity, and important for correct gynoecium and fruit development in Arabidopsis. Plant J. 71, 314-326. doi: 10.1111/j.1365-313X.2012.04990.x
Conflict of Interest Statement: The authors declare that the research was conducted in the absence of any commercial or financial relationships that could be construed as a potential conflict of interest.

Received: 09 January 2014; paper pending published: 08 March 2014; accepted: 19 March 2014; published online: 07 April 2014.

Citation: Wynn AN, Seaman AA, Jones AL and Franks RG (2014) Novel functional roles for PERIANTHIA and SEUSS during floral organ identity specification, floral meristem termination, and gynoecial development. Front. Plant Sci. 5:130. doi: $10.3389 /$ fpls.2014.00130

This article was submitted to Plant Evolution and Development, a section of the journal Frontiers in Plant Science.

Copyright (c) 2014 Wynn, Seaman, Jones and Franks. This is an open-access article distributed under the terms of the Creative Commons Attribution License (CC BY). The use, distribution or reproduction in other forums is permitted, provided the original author(s) or licensor are credited and that the original publication in this journal is cited, in accordance with accepted academic practice. No use, distribution or reproduction is permitted which does not comply with these terms. 